\title{
Issues on the Conviction of New Types of Drug Crimes
}

\author{
Jiangfeng Xiao \\ China University of Political Science and Law, Beijing, China \\ Email: na.jiang@bnu.edu.cn
}

How to cite this paper: Xiao, J. F. (2020) Issues on the Conviction of New Types of Drug Crimes. Chinese Studies, 9, 65-76. https://doi.org/10.4236/chnstd.2020.93006

Received: May 31, 2020

Accepted: July 31, 2020

Published: August 3, 2020

Copyright $\odot 2020$ by author(s) and Scientific Research Publishing Inc. This work is licensed under the Creative Commons Attribution International License (CC BY 4.0).

http://creativecommons.org/licenses/by/4.0/

\begin{abstract}
In re China jurisdiction, the primary legal sources for conviction of drug related offenses are Criminal Law, accompanied by related judicial interpretations. On top of that, the Controlled Varieties and "Supplementary List" of Narcotic Drugs and Psychotropic Substances with Non-Medical Use is included as a legal source in the process of conviction; In re the conviction of new types of drug offenses, the importance should be attached on the difference between "knowingly" and unreasonable legal mistake in the context of mens rea. For the latter issue, the reasonableness of mistake of legal mistake should be tested on the ground that whether the particular mistake could be foreseeable. Where the legal mistake is found foreseeable, that mistake could not negate the liability of the defendant, neither influence the sentencing imposed on that defendant. On the contrary, the inevitable legal mistake is contributed to negate the liability or mitigate the sentencing. On top of that, where narcotic and psychotropic drugs produced by state's authorized enterprises in compliance with prescribed standard are involved in drug-related crimes is at issue in the underlying case, the evaluation on the quality of drug should be conducted, in the case that the packed drug is unpacked.
\end{abstract}

\section{Keywords}

New Types of Drugs, Identifying Authority, Knowingly,

Unreasonable Legal Mistake

\section{Introduction}

As the first-generation traditional drugs such as heroin and cannabis, accompanied with the second-generation traditional synthetic drugs such as methamphetamine and ecstasy are still rampant, the abuse of new psychoactive substances (thereinafter NPS) is emerging. New psychoactive substances, also known as 
"designer drugs" or "laboratory drugs", are a range of drugs that have been designed to mimic established illicit drugs in order to escape from crackdown, which induce a similar or even stronger cordial, psychoactive and narcotic effect than controlled drugs. In recent years, NPS has spread rapidly due to their variability in chemical structure, appearance, and concealment of usage, and have become the third-generation drug that has become popular globally following traditional drugs and synthetic drugs. It has also become a concern of the international community. ${ }^{1}$ New types of drug offenses not only refers to the novelty in the context of the types of drugs, but it also relates to constantly innovating criminal means. The characteristics of new types of drugs have led to many newly raised problems in the process of conviction of related drug crimes. The great controversy in the process of adjudication with regard to those issues has never stopped, which are highly worthy for further research. This paper will be introduced by three cases involving new types of drug, and further the research on the issues, separately concerning the legal sources of the conviction of new types of drug, the determination of mens rea, and the evaluation on the narcotic and psychotropic drugs streaming into illegal market.

\section{Issues Led by the Advent of New Types of Drug Offenses}

Case 1: A procuratorate in Henan Province filed an indictment before the court pursuant to the Minutes Concerning Issues Related to Narcotic Drugs and Psychotropic Substances with Non-Medical Use (thereinafter "Minutes") jointly issued by Henan Provincial Public Security Department, Procuratorate of Henan Province and Henan Provincial Court. The defendant Mr. Zhao, among the others, was accused for manufacturing and selling drugs of a-PVP (No. 91) listed in the Controlled Varieties and "Supplementary List" of Narcotic Drugs and Psychotropic Substances with Non-Medical Use (thereinafter "Supplementary List"). The "Minutes" states the substances prescribed supra shall be identified as drugs for the criminal enforcement purpose, due to sever addiction. The attorney of the defendant raised the defense that the substances in question are identified as drugs under "Minutes" without the acknowledge of any provisions of Criminal Law or judicial interpretations, which violates the principle of Lenity as well as the Minutes of Wuhan Meeting issued by the Higher People's Court in Wuhan. The attorney suggested that the Standing Committee of the National People's Congress (thereinafter NPC) should review the "Minutes". In order to resolve the disputes mentioned supra, the Supreme People's Procuratorate made an official reply, explicitly stating that the "Supplementary List" can be considered as the authority for drug identification. However, the attorney still advocated that the Administrative Measures for Narcotic Drugs and Psychotropic Substances ${ }^{1}$ The United States has accused China of poor control over fentanyl, which is the major source of fentanyl-like substances in the United States. In response to the concerns of U.S., President Xi Jinping announced China's decision to implement full-scale management of fentanyl substances when he attended the 13th G20 Summit and met with President Trump on December 1, 2018. On April 1, 2019, the Ministry of Public Security and other departments jointly issued an announcement to include fentanyl-related substances into the control list. 
with Non-Medical Use (thereinafter "Administrative Measures") and the attached "Supplementary List", shall not be served as the authority for identifying drugs, since those two documents fall out of the compass of "national regulations".

Case 2: Beijing police has cracked down a series of offenses involving selling "Liquid G-Spot Rhino" online since August 2018. The major component of "Liquid G Spot Rhino" is 5-MeO-DiPT, which is categorized as tryptamine hallucinogen with psychedelic and aphrodisiac effects. It is a kind of new psychoactive substance, and is mainly used in the same-sex intercourse. This substance was included in the "Supplementary List" (No. 96) in 2015. The criminal suspects involved in these cases almost defended themselves on the grounds of reasonable legal mistake, arguing that they knew nothing about the law and lacked the actual knowledge that "Liquid G Spot Rhino" was illegal drug.

Case 3: A drug addict sold methadone which he obtained by spitting out the methadone he took without swallowing, after receiving the treatment in a methadone maintenance treatment clinic. The methadone exclusive for drug treatment operated in the outpatient clinic is produced by state-authorized manufacturers in compliance with standard specifications. The controversy is whether the act of possessing methadone in secret should be reliable for criminal punishment, if doing so, the further question is what is the threshold to initiate the prosecution with regard to the quantity and quality of the drug.

In re cases mentioned supra, a series of issues arise out of the conviction of the new types of drug offenses in the criminal adjudication. Firstly, what is the authoritative regulation for determining whether a specific substance falls within the compass of "drug". Secondly, whether the unreasonable legal mistake is an affirmative defense for the defendant? How to rule the merits concerning "knowingly" as well as the reasonableness of legal mistake? In addition, how to interpret and apply the provisions of Paragraph 2 of Article 1 of the Interpretation of the Supreme People's Court on Several Issues Concerning the Application of Law in the Trial of Drug-Related Criminal Cases (thereinafter "Drug Interpretation"), that is, how should the law apply to the use of narcotic drugs and psychotropic substances in drug crimes produced by state-designated manufacturers according to standard specifications. The analysis will be commenced as follows.

\section{The Legal Basis for Identifying "Drugs"}

\subsection{The New Perspective on the Conviction of New Types of Drug}

In re traditional drug-related offenses, almost no one will doubt the nature of the drug per se. Opium, heroin, cocaine, methamphetamine, etc. are drugs, which are in compliance with both legal provisions and common sense. However, with the advent of new psychoactive substances, the nation has been challenged. Most of the new psychoactive substances, whose names do not appear in the criminal law or judicial interpretation, are also far away from people's daily life. The 
emerge of it leads to the question of what are drugs for the purpose of criminal enforcement. In Cases 1 and 2, it was argued that the substances involved shall not be determined as drugs. The main reasons are: 1) There is absent provision in the criminal law and judicial interpretation. According to Article 357 of the Criminal Law, the term "narcotic drugs" as used in this Law means opium, heroin, methylaniline (ice), morphine, marijuana, cocaine, and other narcotic and psychotropic substances that can make people addicted to their use and are controlled under State regulations. Several judicial interpretations issued by the Supreme People's Court have determined that some narcotic drugs or psychotropic substances are drugs, but the substances involved in the cases have not been included yet. Whether the substances deemed as drug in the context of criminal law is vested in the power of legal interpretation. The "Minutes" identifies substances as drugs absent any authority under the criminal law and relevant judicial interpretations, which violates the principle of Lenity and abuses its authority. 2) There are logical errors in the "Minutes" for identifying drugs. Logically speaking with the "Minutes", as long as narcotic and psychotropic substances that can make people addicted to their use and are controlled under State regulations, they should be deemed as drugs. This logic is obviously wrong. Otherwise, it will lead to an absurd conclusion that the controlled narcotic and psychotropic drugs for medical use produced and sold by administratively licensed enterprises are also drugs for the purpose of criminal enforcement. 3) Pursuant to the Minutes of Wuhan Meeting, if a perpetrator sells narcotic and psychotropic substances to the drug smugglers, traffickers, or individuals who abuse drugs, the perpetrator shall be convicted of drug trafficking. Under this regulation, in order to identify narcotic drugs or psychotropic drugs controlled under State regulations as drugs, the requirements of specific-intent and "actual knowledge of the destination of drugs" must be met simultaneously, that is, the perpetrator knowingly provides drugs to the criminals who smuggle or sell drugs, or individuals who abuse drugs, and the drugs flow to the drug market for drug abusing. It runs afoul of the requirements mentioned supra, when any substances at issue are deemed as drugs.

\subsection{The Critics on the New Perspective}

The author advocates that the opinions supra are debatable. Under Article 357 of the Criminal Law, in addition to drugs whose names are explicitly enumerated in the criminal law and judicial interpretation, other narcotic drugs and psychotropic substances are deemed to be drugs subject to two conditions: "make people addicted to their use" and are "controlled under State regulations". The former can be called the factual element of drug definition, and the latter can be called the legal element of drug definition. The substances involved in cases 1 and 2 are all narcotic drugs and psychotropic drugs controlled under State regulations and shall be considered as drugs.

First of all, there is no dispute that the substances involved meet the factual requirement of the definition of drugs. Narcotic drugs and psychotropic sub- 
stances are regulated by the state because they can get people addicted to them. In the past, Measures for the Control of Narcotic Drugs and Measures for the Control of Psychotropic Drugs clarified the concept of narcotic drugs and psychotropic drugs: narcotic drugs refer to drugs that are prone to have a physical dependence and addiction after continued use; psychotropic drugs refer to drugs that act directly on the central nervous system to excite or inhibit it and the continuous use of drugs can cause dependency. As a superseding law, the Regulations on the Control of Narcotic Drugs and Psychotropic Drugs (hereinafter referred to as the "Regulations"), succeeds the spirit of the aforementioned two "Measures". The "Administrative Measures" has a clear definition of narcotic drugs and psychotropic drugs with non-medical use, that is, substances that are not produced and used as drugs, with addiction or addiction potential and are easily abused. According to the Dependence Conversion Table of 104 Non-Medical Narcotic Drugs and Psychotropic Substances, the conversion ratio of the substance involved in case 1 to methamphetamine is $1: 0.4$, and the conversion ratio of the substance involved in case 2 to methamphetamine is $1: 1$, both of which have the characteristics of addiction effect, and obviously meet the factual requirements of the criminal law on the definition of drugs.

Secondly, the substances involved are controlled under State regulations meeting the legal requirements of the drug definition. The opinions mentioned supra hold to the opposite, because there is a deviation in the understanding of the management system of narcotic drugs and psychotropic substances in China. According to China's management system, narcotic drugs and psychotropic substances are classified into medical and non-medical categories. There is a dynamic adjustment between the two. For example, if the non-medical narcotic drugs and psychotropic drugs are included in the catalog of medicines for having medical application, they will no longer be included in the controlled varieties of narcotic drugs and psychotropic drugs with non-medical Use. At present, China's laws and regulations related to the management of narcotic drugs and psychotropic drugs, are mainly the "Regulations" with the attached "List", as well as "Administrative Measures" with the attached "Supplementary List". The relationship between them shall be correctly clarified. Firstly, In re the relationship between the "Regulations" and the "Administrative Measures", the former makes basic stipulations for the management of narcotic drugs and psychotropic drugs, while the latter makes only detailed and special provisions for the management of non-medical narcotic drugs and psychotropic drugs without changing the nature of them. In other words, the narcotic drugs and psychotropic drugs with non-medical use stipulated in the "Administrative Measures" are also narcotic drugs and psychotropic drugs, which are substances that are juxtaposed with medical narcotic drugs and psychotropic drugs, but not juxtaposed with narcotic drugs and psychotropic drugs. Therefore, unless the "Administrative Measures" prescribes otherwise, the "Regulations" supersedes any other regulations. For instance, as stipulated in the "Administrative Measures", the management of non-medical narcotic drugs and psychoactive drugs required for 
scientific research and experiments, and the standards and reference substance of non-medical narcotic drugs and psychoactive drugs required in the production and testing of drugs and medical devices, as well as the intermediates of non-medical narcotic drugs and psychoactive drugs in the production process of drugs, shall be in compliance with the relevant provisions. The relevant regulations herein first refer to the "Regulations". Secondly, this conclusion can also be proved from the relationship between the "List" and "Supplementary List". According to the "Administrative Measures", unless the listed varieties of the narcotic drugs and psychotropic drugs are regulated otherwise, the newly added controlled varieties of non-medical narcotic drugs and psychotropic drugs are listed in the schedule of this method (namely, the attached "Supplementary List"). In other words, the reason why it is called "Supplementary List" is actually an addition to the newly added varieties of the "List", and the two shall obviously be used together. Therefore, the fundamental reason why the judicial organs identify the substances involved as drugs is that the "Regulations" and the "List" are national regulations and can be considered as the authority for the identification of drugs. If the substances prescribed in the "Regulations" and "List" are drugs, the substances referred to in the "Administrative Measures" and the "Supplementary List" are also drugs. Non-medical narcotic drugs and psychotropic drugs are subject to stricter control because they are not used for proper purposes in medicine. The view that the "Administrative Measures" and the "Supplementary List" are departmental regulations and cannot be considered authoritative for identifying drugs is the result of distorting the relationship among several regulations, which obviously cannot be established. Thirdly, the "Regulations" per se does not list any substance names, and the "List" concerning the names of substances is jointly issued by relevant departments in the formality of "notices". The "List" and "Supplementary List" are similar in terms of specifications and forms. It is not deniable that the "List" is an authoritative basis for identifying drugs, and thus the reasons for denying the authority of the "Supplementary List" are insufficient. Published as an attachment to the "Administrative Measures", the "Supplementary List" is only technical considerations for formulating and publishing regulations, and does not affect its authority. The reply of the Supreme People's Procuratorate explicitly stated that the "Administrative Measures" and "Supplementary List" were enacted under the authorization of Paragraph 2, Article 3 of the "Regulations", and the "Supplementary List" can be used as the authority for identifying drugs, which obviously conveys the same opinion.

Thirdly, the opinions mentioned supra misunderstood the original intention of judicial interpretation. According to the above opinions, the Supreme Court has confirmed that 29 kinds of narcotic drugs and psychotropic substances are drugs for the criminal enforcement purpose through judicial interpretation. The substances involved are not listed in the judicial interpretation and cannot be identified as drugs. This is obviously a misreading of the relevant judicial interpretation. The article Understanding and Application of the "Interpretation of 
the Supreme People's Court on Several Issues concerning the Application of Law in the Trial of Drug-Related Criminal Cases" published by People's Judicature in 2016 expressly stated that according to the List of Narcotic Drugs or the List of Psychotropic Drugs of the 2013 edition, there were a total of 270 kinds of controlled narcotic and psychotropic drugs (Ye Xiaoying, Ma Yanshi, Fang Wenjun, \& Li Jingran, 2016). Given that the judicial interpretation is not possible to set forth the threshold for the conviction and sentencing for all controlled narcotic and psychotropic drugs, therefore, the "Drug Interpretation" mainly solves the current conviction and sentencing standards for drugs that have been abused on a certain scale or have a high potential for abuse. For other abuse issues that are not yet prominent or have little potential for abuse, no provision has not been enacted yet. It can be concluded that the basic position of the Supreme Court on this issue is also distinguishable, that is, all controlled narcotic and psychotropic drugs (no distinction between medical and non-medical use have been made) may be considered as drugs.

Finally, the relevant provisions of the Minutes of Wuhan Meeting shall be correctly applied. Because narcotic drugs and psychotropic drugs with medical use have dual attributes of both pharmaceuticals and drugs, the Minutes of Wuhan Meeting stipulates that psychotropic drugs and narcotic drugs produced by formal manufacturers flowing into illegal channels are drugs. However, it is certainly not suggesting that psychoactive drugs and narcotic drugs with non-medical use must be identified as drugs, and they must also meet the requirements of "knowingly" and "clear destination". The "Administrative Measures" explicitly purports that any entity or individual is prohibited from producing, trading, transporting, using, storing and importing and exporting psychoactive drugs and narcotic drugs with non-medical use. Therefore, there are basically no proper channels for psychoactive drugs and narcotic drugs with non-medical use in China, and they mainly have the characteristics of drugs, which shall be considered as drugs.

\section{Mens rea and Reasonableness of Legal Mistake}

In traditional drug crimes, no one would argue that he does not know that opium, heroin, etc. are drugs. The traditional drug crime basically has borne an attribute of Malum in se after a long period of time. However, the new types of drugs are different, and they are often controlled in accordance with the provisions of administrative regulations. A majority of new types of drugs have been proscribed for a very short period of time with the obvious attribute of Malum prohibitum. In this case, the perpetrator's defense that he was not aware that the substances were drugs under state control could not be considered as unreasonable. Some opinions believe that under such circumstance, it should be determined based on the defendant's confession. If a perpetrator does not know that this substance is a drug under the state control, then he lacks the specific intent of selling drugs, and is not liable for the underlying offense. According to such 
opinion, as long as the criminal suspect does not make relevant confessions, he will be acquitted of a charge. This rule will affect the fight against new types of drug crimes. In practice, the idea of some authorities in charge is to find evidence to prove that the perpetrator knows or should have knew that the substance involved is a drug controlled under state regulations. In Case 2, no criminal suspect admitted that the substance in question was drugs controlled by the state. The investigatory authority tried to prove whether the perpetrator possesses the actual knowledge that the substance involved was a state-controlled drug based on whether the perpetrator was homosexual or whether he had used the substance.

The author believes that the notion mentioned supra go wrong. On the one hand, if the perpetrators trafficking in opium, heroin, and methamphetamine raise the defense that they did not know that these are drugs, no one would think that such excuses negate the required mens rea. In re new types of drug crimes, can the defense be permissible only because the drugs in the underlying case are newly under the control by authority? So how long will it take for the state control to stop making it an intentional crime? This is a question that cannot be answered at all. On the other hand, whether it is thought that being a gay should be knowingly or that one should have knew after using it, is not on a sound ground. In fact, the material matter is how to identify the "knowingly" in the context of drug-related crimes and how to deal with the reasonableness of legal mistake. If these two problems are solved, such cases can be properly handled.

First of all, the "knowingly" in the mens rea of drug crimes is with the compass of "general intent", which is prescribed in the General Provisions of Criminal Law. In addition, the specific provisions of Criminal Law also provide "knowingly" for certain specific crimes, which are called "specific intent". For example, "knowingly" prescribed in the crime of possession and use of counterfeit money, falls squarely with "specific intent". Only the "specific intent" is requires the offender possesses the actual knowledge of the nature of objects in question. In re drug trafficking prescribed in Criminal Law, there is no requirement of such "specific intent". This means that the actual knowledge is not required. The crime of drug trafficking, as an intentional offense, requires only general knowledge, which cannot be measured with the aid of professional knowledge, but should be confirmed by the reasonable person with the aid of the common sense. Just as for those who sell obscene articles, they do not need to know how the obscene articles are defined in the law, nor do they need to know that their act constitutes a crime. As long as they knew the content of the discs they sell at the time of commitment of crime, they knew that this may be illegal, and they possess the required intent.

Secondly, it is necessary to accurately distinguish the legal mistake from factual mistake. No matter what kind of intent is mentioned above, it is concerning the mens rea as an element of crime. The perpetrator's knowledge for the purpose of justification will involve two parts of facts: plan facts that do not need the aid of evaluation, such as "train", "currency" and "women", etc.; facts that need 
the aid of evaluation, such as "erotic books" and "precious birds", etc. The latter facts should be justified within the defense of legal mistake, rather than factual mistake (Feng Jun, 1996). The weight and function of the two in the criminal prudence are completely different, and the methods of examination and judgment in the handling of specific cases are also very different. According to this classification, whether a substance is a drug controlled under State regulations and whether trafficking violates the criminal law is obviously within the realm of legal mistake. The lack of actual knowledge of the facts constituting the factual mistake, which is an affirmative defense for intentional crime. For example, a perpetrator bought a packet of flour from the market and took it home to cook, but in fact it was a packet of drugs. Obviously, the perpetrator did not possess the actual knowledge of the substance in question, thus he lacked the intention of a drug-related crime. On the other hand, reasonable legal mistake is not an affirmative defense for justification, but a defense for excuse. For instance, the perpetrator knew that he bought narcotic and psychotropic drugs, but did not know that the drugs had just been declared to be controlled. This is a legal mistake. It cannot be justified, but it can be raised to negate culpability. In drug crimes, special attention should be paid to distinguish between the two. Because "knowingly" in the expression of "possessing actual knowledge that it is a drug for selling" may have a double meaning, which may refer to cognition of facts, such as drugs or flour; or also refer to evaluating cognition, that is, whether it is a drug for the purpose of legal enforcement. The case 2 mentioned did not correctly distinguish the two cognitions, and the method of proving factual knowledge is used to replace the review of legal mistake, which results in the difficulty of adjudication.

Thirdly, the legal mistake should be solved through the examination of the reasonableness of mistake. A person who committed an act proscribed by the criminal law, failed to acknowledge the illegality of his own behavior, which is called legal mistake under the criminal law prudence. In re new types of drug crimes, this issue is more radical. The list of narcotic and psychotropic drugs under State control is constantly being updated, which probably cause the legal mistake. However, there is no sound ground to advocate that legal mistake leads to negate a crime. There have been two dominating views on the relationship between the legal mistake and conviction. One is, to deny any relationship existing between the legal mistake and conviction, which believes that the conviction of a perpetrator "does not change due to subjective misunderstanding" (Yang Chunxi \& Yang Dunxian, 1994). The rationale is that this theory fears that the perpetrator would abuse the legal mistake as an excuse to evade conviction. Its view can be summarized as "ignorance of the law excuses not". The other theory emphasizes that legal mistake is an indispensable component of conviction. It is believed that citizens' ignorance or even misunderstanding of the law is the state's failure to teach, and the punishment imposed on those who fail to apprehend the law is a serious violation of the original meaning of culpability (Chen Xingliang, 2005). This point of view can be summarized as "ignorance of 
the law is no excuse". Along with the overwhelming emergence of statutory provisions concerning Malum prohibita, which are difficult to be acknowledged with the common sense, while the task of criminal law to regulate crimes and protect society is increasingly heavy, simply emphasizing that "ignorance of the law excuses not" and "ignorance of the law is no excuse" does not work. The opinion believes that the perpetrator is acquitted of drug crime, on the grounds of "ignorance of the law is no excuse", which is inconsistent with China's current rule of law, legal provisions, and judicial practice. There are theoretical solutions to this problem. For example, some scholars suggested that a review process should be imposed on the reasonableness of legal mistake. For situations where there may be a legal mistake, it is necessary to examine whether the actor has the opportunity to understand the law and avoid the possibility of legal mistake. If the legal mistake is inevitable, then an acquittal or mitigated punishment may be considered. On the contrary, as long as the wrong cognition of illegality is avoidable, the acquittal is not guaranteed. In this situation, the unreasonable legal mistake is at most a factor for sentencing (Che Hao, 2017).

Finally, the issues involved in Case 2could be solved in the context of legal mistake. For Case 2, there is no need to prove that a perpetrator knows or should have knew the legal provisions, because once the "Administrative Measures" and "Supplementary List" are published, it should be presumed that everyone knows, since China has also carried out expansive and intensive publicity on narcotic and psychotropic drugs. The perpetrators in the underlying case, regardless they are Taobao suppliers, purchasers or end users, regardless they are homosexual or not, have opportunity to learn about the law so as to avoid mistakes, unless in extreme situations such as extremely remote and underdeveloped areas in which they do not have a fair chance to know of the law. If a perpetrator fails to learn about the law, a conclusion should be drawn that legal mistake can be unreasonable; if a perpetrator can prove that he has taken reasonable measures to learn about the law but still has legal mistake, therefore, it can be concluded that the legal mistake is reasonable. For example, when a perpetrator committed the offense under the wrong legal documents of the judiciary authorities and mistakenly believed that his behavior was legal. According to this, as long as it is evident that the perpetrators have doubts about the legality of "Liquid G Spot Rhino" (for example, some perpetrators clearly know that it is a product without a production license, a product inspection certificate, or a factory name, and cannot be sold in hospitals and pharmacies; some perpetrators told purchasers that the investigation was strict, the medicine was strong, and less product should be used; some perpetrators are homosexual and used for a long time, resulting in hallucinations or dependence; some perpetrators adopted abnormal transaction methods such as separation of people and goods, etc.), if they cannot prove that they have worked hard to learn about the law, it can be inferred that their legal mistake is unreasonable, which does not sufficiently negate the conviction of a drug-related crime. If there is no evidence to prove that the perpetrators should have doubted about the legality of "Liquid G Spot Rhino", the justice calls with- 
drawal of prosecution, mitigation of culpability or acquittal, depending on the specific circumstances.

\section{Application of Paragraph 2 Article 1 of the Drug Interpretation}

According to the "Regulations", the State imposes strict controls on the plants for producing narcotic drugs as well as narcotic and psychotropic drugs. Unless "Regulations" stipulates otherwise, no entity or individual may plant plants for producing narcotic drugs, as well as conducting experimental research, production, distribution, use, storage and transportation of narcotic drugs and psychotropic drugs. Methadone is in the list of narcotic drugs subject to strict control for its medical effects in the treatment of detoxification of heroin addicts and as a substitute for maintenance therapy. The "Drug Interpretation" set forth the threshold for conviction and sentencing standards for drug crimes involving methadone. In the meanwhile, to reasonably determine the count of offenses, to advance judicial efficiency, and to avoid unnecessary repeated identification, according to Paragraph 2 of Article 1 of the Drug Interpretation, where the narcotic drugs or psychotropic drugs manufactured by state-authorized manufacturers in compliance with the standard specifications used in drug-related crimes, the amounts of drugs involved in such crimes shall be determined according to the drug quality in the pharmaceuticals. This article is controversial when it comes to Case 3. First, whether the Paragraph 2 Article 1 of the Drug Interpretation referred in the "a large amount of any other drug" applies to Article 2 of "a relatively large amount of any other drug"; second, whether the drug quality should be determined in such cases. In re issues mentioned supra, the author believes that the following two points should be considered. First, provided that the strict national control over the production of narcotic drugs and psychotropic substances for medical use, the stability of the quality of narcotic drugs and psychotropic substances produced by state-authorized manufacturers is guaranteed. Therefore, unless it is of probability by evidence the opened medicines were contaminated, it's not necessary to identify the quality. From the perspective of the principle of interpretation on criminal law, the Articles 1 and 2 of Drug Interpretation is designed to merely advance charging separate offenses in multiple counts and imposing concurrent sentencing. For the crime of "a large amount of any other drug" stipulated in Paragraph 1 Article 1, the amounts of drugs involved in such crime shall be determined according to the drug quality in the pharmaceuticals. For the same crime of "a relatively large amount of any other drug" stipulated in Article 2, it shall be handled the same way. Secondly, concerning the specific Case 3, whether this provision can be applied or not requires specific analysis of specific issues. In general, the provisions of the Paragraph 2 of Article 1 of the Drug Interpretation are aimed at narcotic drugs or psychotropic drugs produced by state-authorized manufacturers according to standard specifications, mainly referring to drugs that have not been unpacked. If the package has been unpacked, it can no longer guarantee that the composition and 
nature of the pharmaceuticals have not been changed, so it is inappropriate to directly apply the provisions of this paragraph. If the packages of the pharmaceuticals have been unpacked, since the quantity of drugs is determined based on the content of the drug in the pharmaceuticals or the actual weight of the drugs, the results of sentencing will be very different, so the content and composition identification shall be carried out. Only if the appraisal result does not change significantly compared with the content and composition of the original pharmaceuticals, can the number of crimes be determined in accordance with Paragraph 2 of Article 1.

Conclusively, since new types of drug is disparate with traditional drug in the context of nature, physical characteristics and restrictive ground. In the meanwhile, the legal ground on the conviction of new types of drugs should be expressively regulated. The test of mens rea involving new types of drug offenses should be set forth. The evaluation on the quality of new types of drug should be understood for its significance. Those aspects are tremendously significant to strike against new types of drug offenses.

\section{Conflicts of Interest}

The author declares no conflicts of interest regarding the publication of this paper.

\section{References}

Che, H. (2017). Structure of Staged Theory of Criminal (p. 250). Beijing: Law Press.

Chen, X. L. (2005). Study on Reasonableness of Legal Mistake. China Legal Science, No. 5, 133-143.

Feng, J. (1996). Criminal Liability (p. 153). Beijing: Law Press.

Yang, C. X., \& Yang D. X. (1994). China Criminal Law (p. 94). Beijing: Beijing University Press.

Ye, X. Y., Ma, Y. S., Fang, W. J., \& Li, J. R. (2016). The Understanding and Application on the Interpretation of the Supreme People's Court on Several Issues concerning the Application of Law in the Trial of Drug-Related Criminal Cases. People's Judicature, No. 13, 22-29. 